\title{
Leo Hendrik Baekeland - Baquelite, o primeiro plástico sintético -
}

\author{
Raquel Gonçalves Maia ${ }^{1}$ \\ Departamento de Química e Bioquímica, Faculdade de Ciências da Universidade de Lisboa \\ rmcgonc@gmail.com
}

Leo Hendrik Baekeland - Bakelite, the first synthetic plastic - What is bakelite?", asks the reporter to passers-by in New York. So begins the documentary "All Things Bakelite: The Age of Plastic". No one knows the answer; and yet, we all live in the "Plastic Age," initiated by Leo Hendrik Baekeland with the invention of the first synthetic plastic: bakelite. It was the year 1907.

Born in Belgium, a doctorate in chemistry from the University of Ghent, Baekeland starts at the age of 21 a promising academic career, along with a commercial enterprise in the field of photography; however, in 1869, he departs to the USA.

His first great invention was the velox, an innovative photographic paper; the industrialization of velox started in the Nepera Chemical Company. Purchase of the patent and of the firm by Eastman Kodak made Baekeland a free and wealthy man. In his own laboratory, after a systematic study of the reactions between phenol and formaldehyde, in a stroke of genius, he invents bakelite - "The material of thousand uses"! In 1910, Baekeland founded the General Bakelite Company, which later gave way to the Bakelite Corporation.

Leo Baekeland, master of an insatiable curiosity and of a high intellectual capacity, was a remarkable chemist. Founder of the modern plastic industry, he well deserves his place in the "Hall of Fame".

\begin{abstract}
"O que é baquelite?”, pergunta o repórter aos transeuntes em Nova Iorque. Assim começa o documentário "All Things Bakelite: The Age of Plastic". Ninguém sabe responder; e, no entanto, todos vivemos na "Era do Plástico", iniciada por Leo Hendrik Baekeland com a invenção do primeiro plástico sintético: baquelite. Corria o ano de 1907. Nascido na Bélgica, doutorado em química pela Universidade de Gante, Baekeland inicia aos 21 anos uma promissora carreira académica, a par com um empreendimento comercial na área da fotografia; em 1869, porém, ruma aos EUA.
\end{abstract}

A sua primeira grande invenção foi o velox, um papel fotográfico inovador; a industrialização do velox nasce com a Nepera Chemical Company. A compra da patente e da firma pela Eastman Kodak fez de Baekeland um homem livre e rico. No seu próprio laboratório, após um estudo sistemático das reações entre fenol e formaldeído, num golpe de génio, inventa a baquelite - “o material de mil usos”! Em 1910, Baekeland criou a General Bakelite Company que, mais tarde, deu lugar à Bakelite Corporation.

Leo Baekeland, senhor de uma curiosidade insaciável e de uma elevada capacidade intelectual, foi um químico notável. Fundador da moderna indústria do plástico, bem merece o seu lugar no "Hall of Fame”.

\section{Nascido e educado na Bélgica}

O primeiro filho do casal Charles Baekeland, sapateiro e analfabeto, e Rosalie Merchie, ex-empregada doméstica, foi Leo Hendrik Arthur Baekeland, nascido a 14 de novembro de 1863 em Sint-Martens-Latem, nos arredores da bela cidade de Gante [1-4].

Foi uma criança precoce. Saber os porquês e eliminar os obstáculos para construir as respostas sempre foram para ele tarefas prementes. Gostava de se opor à opinião generalizada e não prescindia de mostrar a sua diferença. Tinha por ídolo Benjamim Franklin e, mais tarde, juntou-lhe Louis Pasteur.

Com o apoio da mãe, estudou no Ateneu Real, ao mesmo tempo que frequentava aulas noturnas de química, física, fotografia e economia, e trabalhava, em "part-time”, num armazém de venda de produtos químicos e

Professora Catedrática aposentada farmacêuticos. Uma bolsa de estudos levou-o às ciências exatas na Universidade de Gante. Foi "preparador", ainda antes de completar o bacharelato. Seguiu-se o doutoramento em química, sob a orientação de Theodore Swarts (1839-1911). Em 1884, com apenas 21 anos, atingia o grau mais elevado que uma universidade pode conceder. Que grande triunfo!

A Universidade de Gante era altamente conceituada. Em 1958 recebera o notável químico orgânico alemão August Kekulé (1829-1896), que aí lecionou e investigou durante nove anos. Grande parte do seu trabalho laboratorial de renome foi desenvolvido em Gante. Adolf von Baeyer (1835-1917; Prémio Nobel da Química em 1905) foi outro químico de excelência que cruzou a Universidade de Gante. Embora por pouco tempo e bem antes de Baekeland a frequentar, o cariz e qualidade do seu trabalho foram transmitidos aos sucessores. Theodore Swarts, professor brilhante, foi seu herdeiro. 


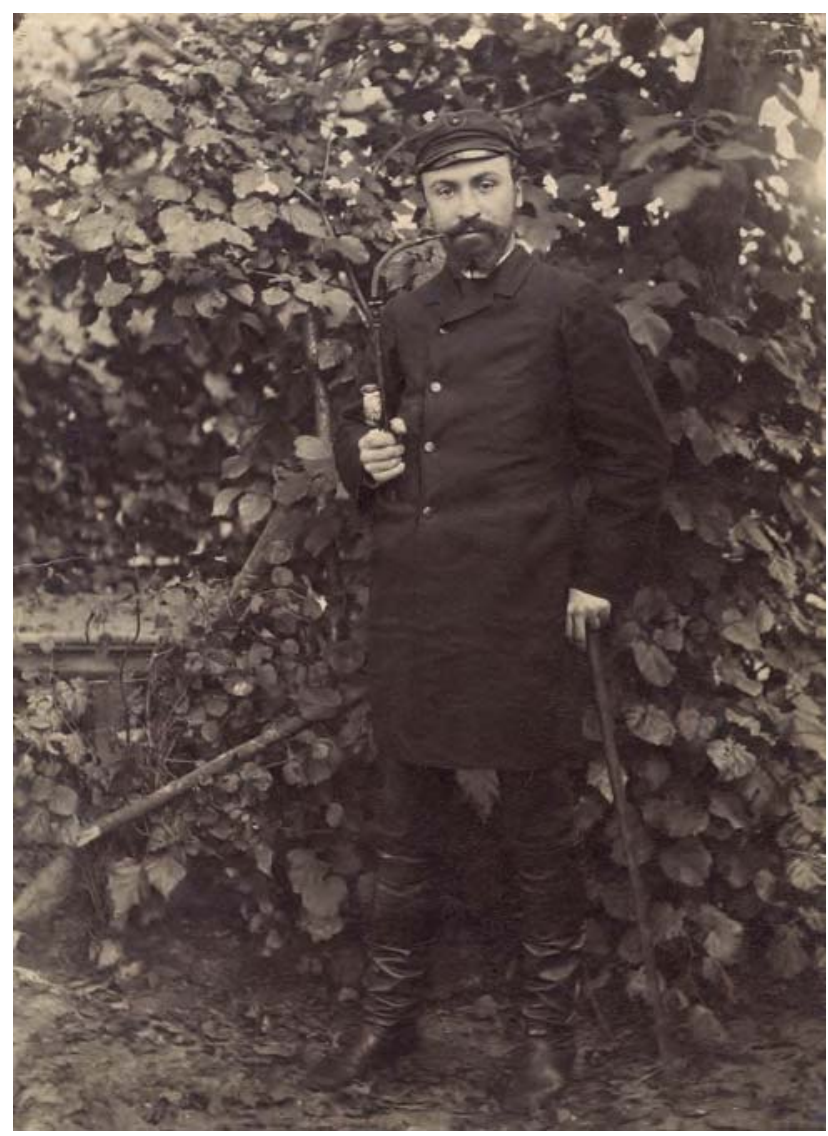

(C) University Archives, Ghent

Figura 1 - O estudante universitário Leo Baekeland.

Logo após a obtenção do diploma de doutoramento “maxima cum laude”, Leo Baekeland vai ocupar o cargo de "Leitor” (Assistente) na École Normale de l'État em Bruges. No ano seguinte é promovido - torna-se professor de química e física. Em 1889 Baekeland regressa à Universidade de Gante, agora como professor-assistente. Estava em marcha uma promissora carreira académica.

Entretanto, o gosto pela fotografia intensificara-se uma interligação evidente entre a química e a ciência da fotografia. À época, o processo fotográfico envolvia uma solução viscosa de nitrocelulose em álcool e éter com outros componentes químicos (cloretos, brometos e/ou iodetos), o colódio, que era aplicada sobre placas fotográficas de vidro. Em contacto com nitrato de prata tornava-se sensível à luz. A placa tinha de permanecer húmida durante todo o procedimento, incluindo a captação e a revelação das imagens. Desenvolveram-se, então, placas de emulsão fotográfica seca, onde gelatina substituía o colódio, o que simplificou o processo. No entanto, a fraca sensibilidade às cores, à graduação tonal preto-branco e as impurezas dos produtos químicos para revelação continuavam a fazer de uma boa fotografia uma "obra do acaso”.

Leo Baekeland procurou a solução, um processo simples e fiável. Para tal, criou a sua própria empresa, a $\mathrm{Dr}$ Baekeland et Cie, em 1888, em sociedade com um colega da Universidade de Gante. Não foi bem sucedido. Concluiu que: "Nada é tão simples como aparece nos livros de texto". Sente-se cada vez mais interessado em aplicações concretas e mais afastado das ideias especulativas que tanto atraem os químicos académicos.

Enquanto recém-graduado das universidades da Bélgica, Baekeland, com um ensaio sobre "fenómenos de dissociação”, obtivera em concurso um prémio monetário para usufruto de estudos no estrangeiro. Era tempo de o utilizar. Em 10 de agosto de 1889 embarca em Antuérpia com destino a Nova Iorque. Não vai só. Com ele segue a sua noiva, Céline Platteau Swarts, filha de Theodore Swarts, com quem casara dois dias antes.

\section{Velox - o papel fotográfico}

Pouco tempo depois de chegar aos EUA, Baekeland conhece Richard A. Anthony, presidente da firma E. \& H. T. Anthony \& Company, uma das maiores fornecedoras e distribuidoras de materiais para fotografia. Richard Anthony oferece-lhe emprego como químico investigador. Baekeland aceita, embora na sua mente anteveja a sua própria empresa e os seus próprios produtos; mas para começar teria um local de trabalho e um salário.

Analisemos o espaço e o tempo em que a ação decorre. Por volta de 1900, muitos eram ainda os que não entendiam o que era ser químico e, muito menos, que podia existir a profissão de químico ligada à indústria. Salvo raríssimas exceções, não existia uma investigação formal na indústria [5].

Decorreram dois anos. Leo Baekeland aperfeiçoou as emulsões de brometo para filme fotográfico, procedeu à obtenção de produtos químicos de pureza adequada e experimentou novas emulsões para papel de impressão. Depois, passou a ser consultor independente. Seguiu-se um período com sérios problemas de saúde e financeiramente desastroso. Porém, a sua concentração na manufatura de um novo papel fotográfico, de uma meticulosidade inexcedível, atraiu o investimento de Leonard Jacobi, um bem sucedido homem de negócios.
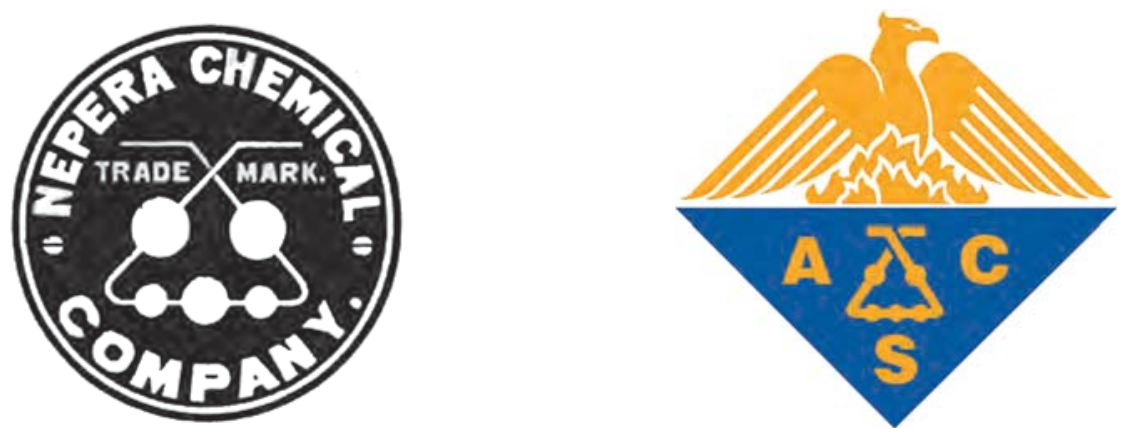

Figura 2 - Logótipos da Nepera Chemical Company e da American Chemical Society (ambos ostentam a reprodução do Kaliapparat) [6]. 
Em 1893, Baekeland e Jacobi fundam a Nepera Chemical Company, em Yonkers, Nova Iorque. O que os movia era a industrialização da fotografia estendida ao papel de impressão - o velox, do latim “veloz”. O velox é um papel fotográfico de emulsão de gelatina e cloreto de prata, manufaturado com controlo da quantidade de sais em uso - a fim de eliminar o passo da lavagem da emulsão. Tinha a vantagem sobre o papel de brometo de poder ser exposto à luz artificial usada na época e, assim, os fotógrafos viam o que faziam e intervinham sempre que necessário. O velox mostrou ter uma impressão duradoira e boa qualidade tonal que não desvanecia com o tempo.

O seu êxito, todavia, não foi imediato. Os fotógrafos profissionais estavam habituados a um certo "saber-fazer" e mostraram relutância à aprendizagem de algo novo. Mas, os “amadores”, de posse das instruções fornecidas pela Nepera, descobriram as imagens fotográficas de qualidade - grandes dinamizadores do velox, o mercado, inevitavelmente, seguiu-os.

À espreita, estava a Eastman Kodak Company. George Eastman, o seu fundador, abordou Baekeland e propôs-lhe comprar a patente do velox e a sua participação na empresa. Muito se tem discutido sobre o avultado quantitativo envolvido... Certo é que a venda do velox fez de Baekeland um homem rico, e a Eastman Kodak reforçou a sua posição dominante no mercado fotográfico.

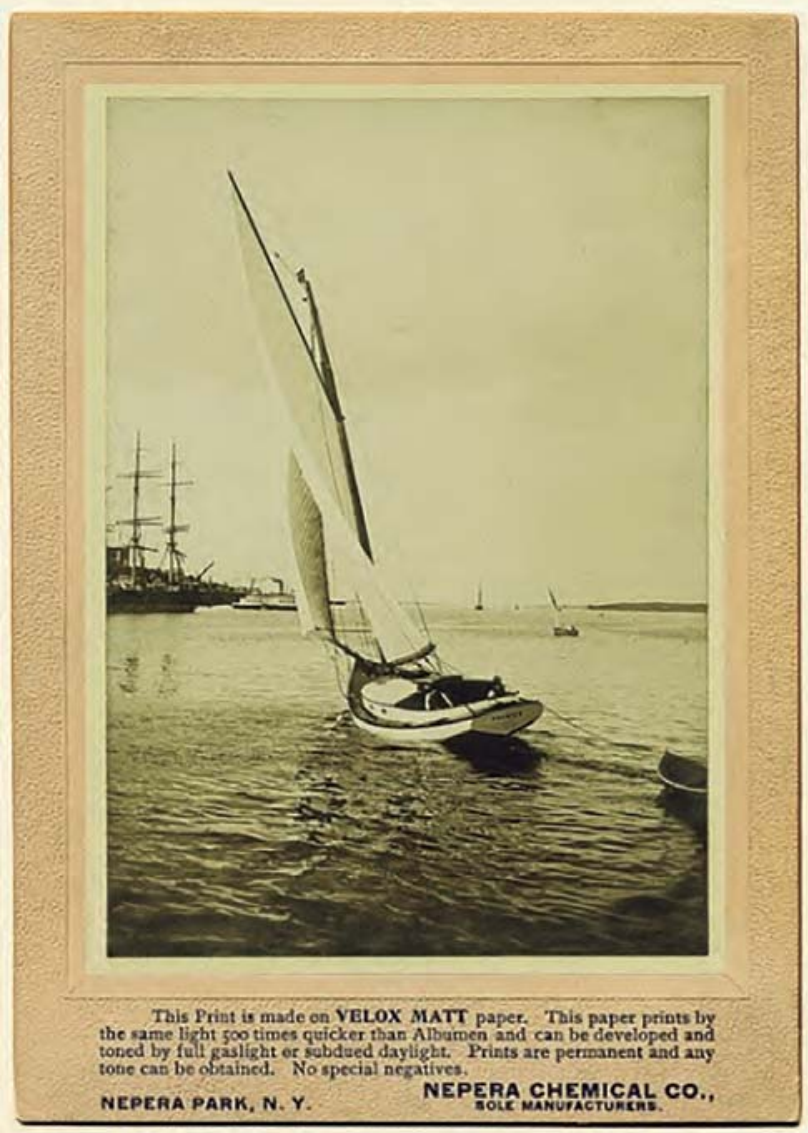

(c) collection Karel Julien Cole Ghent

Figura 3 - Esta impressão é feita em papel VELOX MATT.

\section{Um homem livre}

Em 1899 Leo Baekeland tinha 35 anos e estava exausto. O sucesso do velox, ainda na Nepera, e o dinheiro arrecadado com a venda à Eastman Kodak trouxeram-lhe riqueza e autonomia. Sonhou e concretizou os seus desejos: uma casa, um barco, um automóvel... e um laboratório próprio. “Snug Rock” foi a sua mansão vitoriana em Yonkers, sobranceira ao Rio Hudson. Tinha uma torre coberta de telha onde uma saleta fazia as delícias de Leo - “o meu santuário”. Comprou um pequeno barco, depois o iate de cruzeiro “Cygnet”, e, finalmente, o potente "Ion", com o qual navegava na costa atlântica até à Florida. Uma viatura com um motor de quatro cavalos deu-lhe asas. Em 1906 embarca família, carro e mecânico rumo à Europa. Inglaterra, Escócia, França, Bélgica, Itália... As peripécias comentadas desta travessia de carro pela Europa foram perpetuadas pelo próprio Baekeland numa série de artigos e no livro "A Family Tour Through Europe", densamente ilustrado. Simplesmente fascinante!

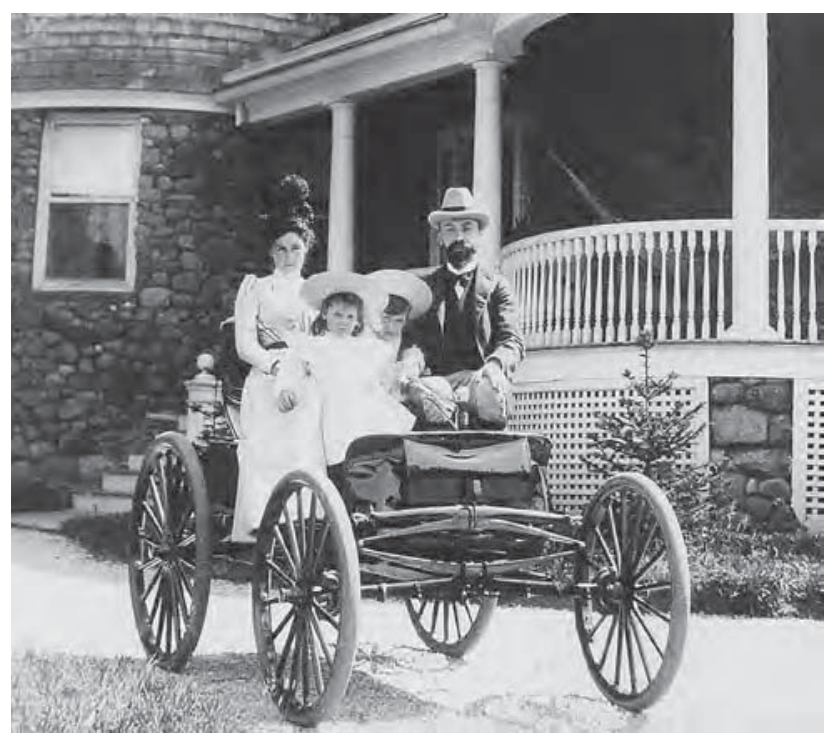

(C) [Leo H. Baekeland Papers], Archives Center, National Museum of American History, Smithsonian Institution

Figura 4 - A Família Baekeland em “Snug Rock”, Yonkers ( 1900$)$.

Um celeiro foi transfigurado em laboratório. Bem equipado, era aí que o químico trabalhava nos problemas “de livre escolha”. Foi aí que, pela primeira vez, foi produzido o primeiro plástico sintético - a baquelite.

Baekeland foi feliz: "o melhor período da minha vida”, escreveu ele num dos seus inestimáveis cadernos de notas. Entretanto, a família crescera. Em 1890, Céline dera à luz uma menina, Jenny, que veio a falecer de meningite aos cinco anos de idade. Depois foi a vez de George Washington (1895-1966) e de Nina (1896-1975). Ambos casaram e foram vários os netos e bisnetos que aumentaram a família.

\section{Baquelite - "The material of thousand uses"}

A primeira menção à Baquelite encontra-se no caderno de notas de Baekeland em princípios de 1907 [7]. Contudo, só decorridos quase dois anos, Baekeland fez a sua revelação oficial. Tal aconteceu num encontro da Secção de Nova 
Iorque da American Chemical Society, que teve lugar no The Chemists' Club. Contou a história da descoberta, discutiu a sua utilidade - com otimismo, mas muito aquém do que o futuro lhe viria a demonstrar - e mostrou peças variadas e perfeitas. Que grande ovação!

Para trás ficava um estudo teórico e experimental exaustivo das reações de fenol com formaldeído, iniciado em 1902 no seu laboratório em Yonkers, com o fim de obter um polímero plástico sintético termofixo - por ser fabricado com novos materiais, sem recurso a precursores naturais, e por ser moldável numa forma determinada e permanente. De forma resumida podemos dizer que Baekeland confirmou que ao juntar aqueles reagentes se formava o álcool salicílico e que este funcionava como um intermediário na polimerização.

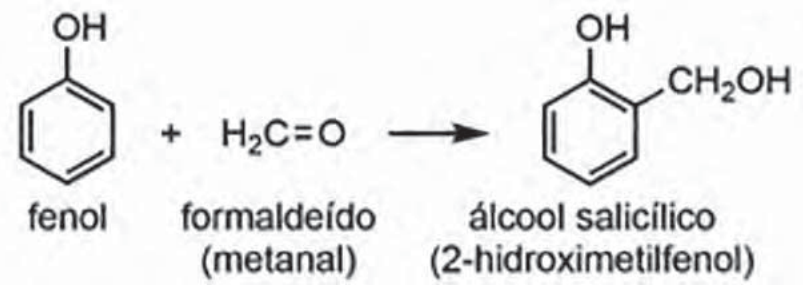

Em meio básico, a polimerização evoluía para a criação de um polímero tridimensional. Controlando as quantidades relativas dos reagentes, Baekeland verificou que obtinha um líquido que progressivamente se transformava num sólido quebradiço. Ainda em estado fusível, pulverizou-o, misturou-o com corantes e colocou-o numa prensa de moldagem. A reação continuou e o produto final tinha a forma desejada. Era um sólido, de estrutura crosslinking, insolúvel, de aspeto semelhante ao do âmbar, sem cheiro. Baekeland tinha encontrado "o material de mil usos". Foi batizado "Bakalite” em 1907, e rebatizado "Bakelite" em 1908, para todo o sempre.

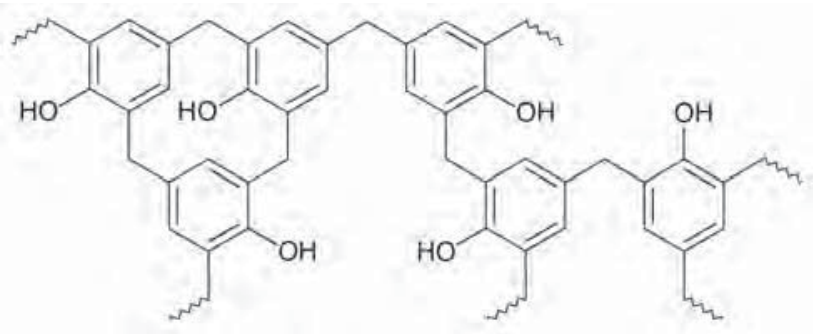

Figura 5 - Estrutura da baquelite.

Um toque de génio vai culminar esta obra. Baekeland compreende de imediato o interesse comercial do produto, e sabe que o processo tem de ser otimizado. Verifica, então, que para aumentar a velocidade da reação na fase final da polimerização, sem esta ser afetada pela libertação de gases, os reagentes devem estar contidos num vaso de pressão. Para isso, construiu um grande “ovo” em aço, medindo cerca de um metro e oitenta de altura - o baquelizador, carinhosamente denominado "Old Faithful" ("Fiel Velho”), pelos primeiros operadores. A peça original encontrou o seu lugar imperecível no Smithsonian's National Museum of American History.

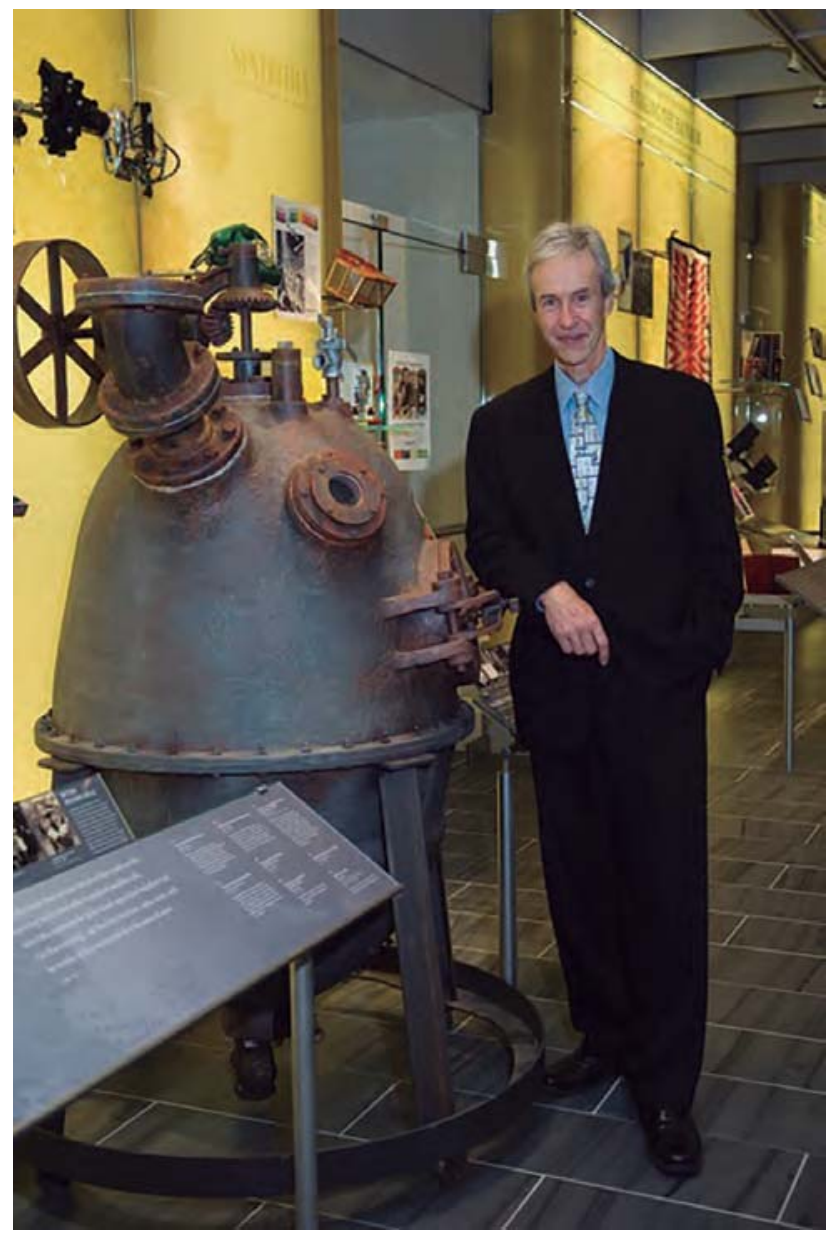

(C) Science History Institute, Filadélfia

Figura 6 - Hugh Karraker, bisneto de Leo Baekeland, posa junto do baquelizador.

Em 1910, Baekeland fundou e foi presidente da General Bakelite Company, que mais tarde deu lugar à Bakelite Corporation. Dez anos depois estimou-se que 43 ramos industriais tiravam proveito da baquelite. Na revista Time-Magazine, datada de 22 de setembro de 1924, com o retrato de Leo Baekeland na capa, podia ler-se: “A partir do momento em que um homem escova os dentes pela manhã com uma escova feita de baquelite, até ao momento em que se deita à noite na sua cama de baquelite, tudo aquilo em que ele toca, vê, usa, será feito deste material de mil usos“ [8].

\section{Plásticos, a caixa de Pandora?}

A baquelite parecia invencível, mas novos plásticos desenhavam-se no horizonte. Dos anos cinquenta em diante a sedução da baquelite esmoreceu rapidamente, suplantada pelos dotes deslumbrantes de outros polímeros plásticos [9]. De uma forma algo sub-reptícia, todavia, a baquelite sobrevive em peças de caráter industrial, em material elétrico e eletrónico, em automobilística, em asas e cabos termorresistentes... e nos leilões de antiguidades Art Deco a preços inacreditáveis!

Na atualidade, a produção mundial de polímeros plásticos excede trezentos milhões de toneladas! Eis a "Era do Plástico” iniciada por Leo Baekeland. Já não com o protagonismo de Baekeland, nem da baquelite, mas do seu legado em termos de paradigma de sucesso. A superprodução 
de plásticos, contudo, levantou uma questão pertinente: como suprimi-los após o seu uso? A sua eliminação pode ser complexa, uma vez que há plásticos que são virtualmente "eternos", como a baquelite, e outros que só se tornarão inofensivos após muitas décadas de decomposição. $\mathrm{O}$ que deitamos fora invade os campos, os rios, os mares e os oceanos, os espaços naturais em que nos orgulhamos de puro respirar - todos os ecossistemas vitais.

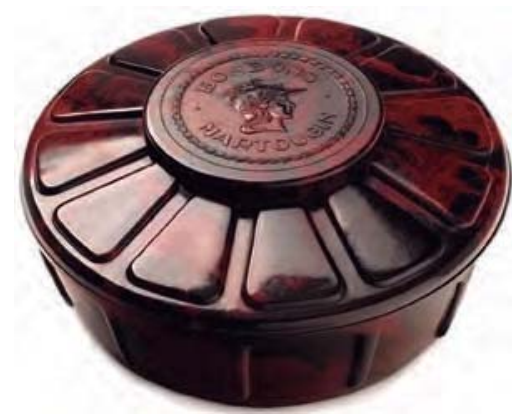

(C) collection Karel Julien Cole Ghent

Figura 7 - Caixa de chocolates Martougin em baquelite [10].

Terá Leo Baekeland aberto a “caixa de Pandora”? Seria utópico, e contraproducente, prescindir da existência dos polímeros sintéticos. Não queremos viver sem “airbags”, sem comida embalada, fresca e nutritiva, sem materiais de construção que nos protejam do frio e do calor excessivos. Queremos dispositivos médicos e próteses que salvam vidas.

A limpeza dos oceanos, a reciclagem, o trabalho conjunto de empresas, governos e cientistas e a educação pública poderão, e deverão, recolocar os plásticos na linha do tempo da evolução do homem.

\section{O seu amor era a investigação}

"O trabalho dos químicos é difícil de entender e ainda mais difícil de ser apreciado pelos não instruídos ou não iniciados; nem os químicos cortejam os aplausos de um público ignorante que não consegue compreendê-los; eles sentem-se totalmente recompensados pelos resultados do seu trabalho se têm a aprovação de alguns colegas químicos, independentemente de lhes trazer lucros financeiros ou não; de facto, a maioria dos químicos está tão apaixonada pelo seu trabalho que muitas vezes negligencia o lado financeiro, em seu detrimento imediato.

Ao contrário do médico, advogado, clérigo, ator, escritor, artista ou homem de negócios, o químico não depende do público em geral; o químico ou está ligado a alguma empresa privada ou atua como consultor ou ensina numa instituição educacional. A popularidade, no sentido usual, tem pouco ou nenhum valor para o químico. Não é de admirar, pois, que os químicos, numerosos e ativos como são, sejam pouco notados entre o ruído diário do jornalismo sensacionalista e a publicidade estridente...”.

Estas palavras de Leo Baeleland, datadas de 1915, fazem todo o sentido na atualidade [11]; mas não deixam de ser surpreendentes para quem teve uma vida ativa e muito próspera.

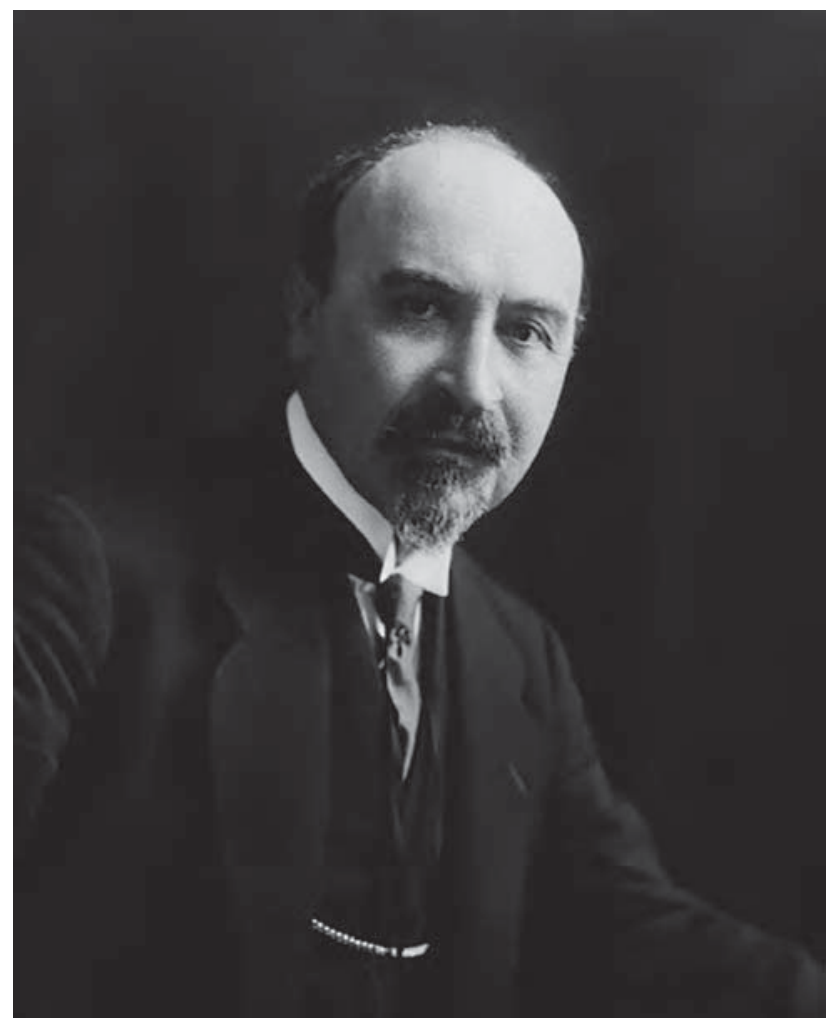

Figura 8 - Leo Hendrik Baekeland ( 1910$)$.

Baekeland foi um homem de invenção com profundo acento científico, nunca um inventor empírico. Dedicou muito tempo da sua vida à aventura comercial de produzir o primeiro plástico sintético - a baquelite. Ganhou somas avultadas com o velox e muito mais ainda com o plástico. Patenteou e protegeu ativamente todas as suas invenções.

Escreveu muitos artigos científicos, crónicas sobre ciência e indústria, educação e ética, sonhos e realidades. Foi membro de diversas sociedades científicas e eleito para a National Academy of Sciences. Recebeu numerosas distinções e prémios. Em 1916 foi-lhe outorgada a Perkin Medal e, em 1940, a Franklin Medal (disciplina: engenharia).

Faleceu em 23 de fevereiro de 1944, em consequência de uma hemorragia cerebral. Postumamente, o seu nome passou a figurar no National Inventors Hall of Fame (1978).

"All Things Bakelite: The Age of Plastic" é um documentário sobre “o pai dos plásticos modernos” [12]. Realizado sob a direção do cineasta John Maher e tendo por produtor executivo Hugh Karraker, ex-ator de teatro, cinema e televisão, bisneto de Leo Baekeland, o filme centra-se na figura do cientista e da sua maior descoberta, a baquelite. $\mathrm{O}$ seu objetivo é colocar Leo Baekeland no pedestal que lhe compete - a par com os grandes inventores que o próprio tanto admirou.

\section{Agradecimento}

A Hugh Karraker, bisneto de Leo Baekeland, pela amável oferta de testemunhos pessoais e disponibilização de fotografias. A Karel Julien Cole (flickr.com/juliensart), pela oferta de fotografias da sua formidável coleção sobre Leo Baekeland e a baquelite. 


\section{Referências}

[1] R. Gonçalves-Maia, "Leo Baekeland - Baquelite, o primeiro plástico sintético”, Coleção "Dos Átomos e das Moléculas”, vol. 6, Edições Colibri, Lisboa (em publicação).

[2] C.B. Kaufmann, "Grand Duke, Wizard, and Bohemian: A Biographical Profile of Leo Hendrik Baekeland (18631944)”, Meta4 Press LLC, 2012; tese M.A., Universidade de Delaware, 1968.

[3] D. Alef, "Leo "Doc" Baekeland: Father of Plastic", Titans of Fortune Publishing, 2009.

[4] R. Gonçalves-Maia, “O Plástico de Baekeland”, em “O Legado de Nobel: Perfis na Ciência do Século XX (19001959)”, Cap. 2, Escolar Editora, Lisboa, 2008.

[5] Nos EUA, o primeiro laboratório de investigação e controlo surgiu na DuPont (abreviatura de E. I. du Pont de Nemours and Company), em Wilmington, Delaware, em 1891; expandiu-se com enorme sucesso nos anos sequentes.

[6] R. Gonçalves-Maia, QUÍMICA - Bol. SPQ n. ${ }^{\circ} 137$ (2015) 53-58.

[7] “Leo H. Baekeland Papers, 1863-1968”, Archives Center,
National Museum of American History, Smithsonian Institution. http://sova.si.edu/record/NMAH.AC.0005

[8] No original: "From the time that a man brushes his teeth in the morning with a bakelite handled toothbrush, until the moment he falls back upon his bakelite bed in the evening, all that he touches, sees, uses, will be made of this material of a thousand uses".

[9] "100+ Years of Plastics: Leo Baekeland and Beyond", T. Strom, S.C. Rasmussen (eds.), ACS Symposium Series, 2012.

[10] Martougin foi uma famosa fábrica de chocolates belga, fundada em 1907 por Alfred Martougin (1875-1952). Na sua "chocolaterie modèle", o chocolate fabricava-se com vários sabores que se correspondiam com nomes femininos: Jemma, Laita, Galba, Minerva, Olympia, Titania... As embalagens eram moldadas pela fábrica Ebena, na Bélgica.

[11] L.H. Baekeland, Science, New Series 42 (1915) 547-555.

[12] “All Things Bakelite - The Age of Plastics", The Life and Times of Leo Baekeland, filme documentário, produtor executivo: H. Karraker; diretor: J. Maher. http://allthingsbakelite.com

Atualidades Científicas

\section{Inserção de $\mathrm{CO}_{2}$ em ligações $\mathrm{C}-\mathrm{H}$}

O desenvolvimento de métodos sustentáveis e eficientes para a utilização de $\mathrm{CO}_{2}$ na indústria química tem sido alvo de intensa pesquisa. Os processos industriais atuais incluem a síntese de ureia, a síntese de Kolbe-Schmitt do ácido salicílico, e a produção de policarbonatos a partir de epóxidos. $\mathrm{O}$ foco na pesquisa tem passado também pela hidrogenação de $\mathrm{CO}_{2}$ com o objetivo da substituição do gás de síntese pelo sistema $\mathrm{CO}_{2} / \mathrm{H}_{2}$. Atualmente, o estudo da formação de ligações $\mathrm{C}-\mathrm{C}$ usando $\mathrm{CO} 2$ segue vias de síntese pouco sustentáveis levando, nomeadamente, à formação indesejada de sais como subprodutos. A formação de ligações $\mathrm{C}-\mathrm{C}$ de forma sustentável a partir de $\mathrm{CO}_{2}$ e de substratos não-ativados seria logicamente iniciada por carboxilação catalítica de $\mathrm{C}-\mathrm{H}$ com formação de ácidos carboxílicos, seguida de posterior hidrogenação com formação de álcoois. No entanto, a inserção de $\mathrm{CO}_{2}$ em ligações $\mathrm{C}-\mathrm{H}$ é termodinamicamente desfavorável. A utilização de uma base e a estabilização do produto formado na forma de um carboxilato torna o processo favorável termodinamicamente. No entanto, os passos seguintes levam inevitavelmente à formação de sais sem valor acrescentado.

Lukas J. Gooßen, da Ruhr-Universität Bochum, Alemanha, e colegas desenvolveram uma estratégia para a inserção de $\mathrm{CO}_{2}$ em ligações $\mathrm{C}-\mathrm{H}$ sem formação de sais como subprodutos. $\mathrm{O}$ método passa pela reação de alcinos terminais com $\mathrm{CO}_{2}$, catalisada por $\mathrm{Cu}(\mathrm{I})$, na presença de uma amina. Subsequentemente, o sal de amónio resultante pode ser hidrogenado cataliticamente, usando um catalisador de ródio/molibdénio, com formação de um álcool primário. Nesta etapa, apenas se liberta água e a amina regenerada pode ser recuperada, tornando o processo geral livre de subprodutos indesejáveis.

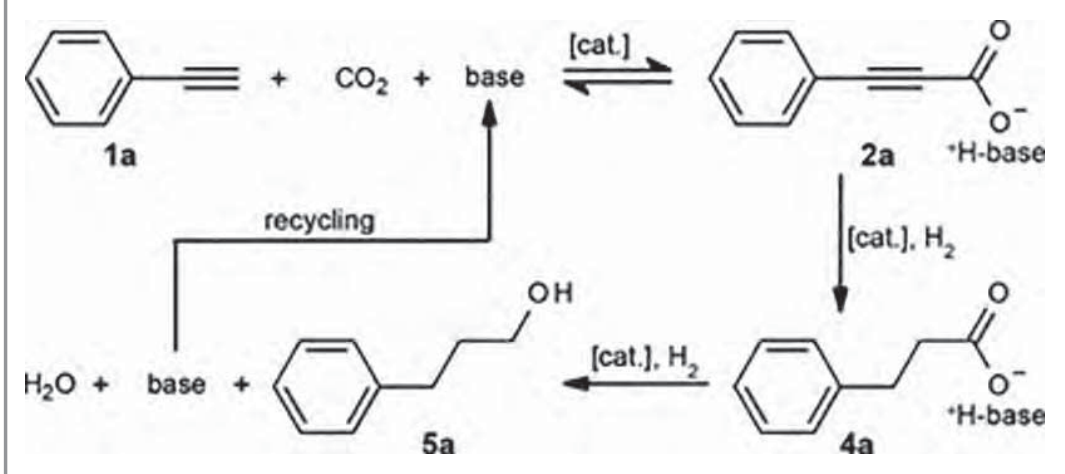

\section{Fontes:}

Insertion of $\mathrm{CO}_{2}$ into $\mathrm{C}-\mathrm{H}$ bonds, http:// www.chemistryviews.org/details/ezine/10998792/Insertion_of_CO2_into_ CH_Bonds.html?elq_mid=26768\&elq_ cid=3941189 (Acedido em 22/04/2018)

T. Wendling, E. Risto, T. Krause, L.J. Gooßen. Salt-free strategy for the insertion of $\mathrm{CO}_{2}$ into $\mathrm{C}-\mathrm{H}$ bonds: catalytic hydroxymethylation of alkynes. Chem. Eur. J. 24 (2018) 6019-6024. 